\title{
PROTEINOGRAMA DO LIQUIDO CEFALORRAQUEANO NA ESQUISTOSSOMOSE MANSONI
}

\author{
IVANILTON GALHARDO : \\ NaIDE GaLhardo ** \\ A. SPINA-FranÇA $*: * *$
}

Scaff, Riva \& Spina-França *, mediante análise de casos de meningomielorradiculopatia esquistossomótica puderam atribuir papel importante à vasculite na gênese dos quadros observados, confirmando achados de Maciel Coelho \& Abath ${ }^{3}$. Os fenômenos de vasculite resultam geralmente da disseminação hematogênica de produtos oriundos da desintegração do parasita. O comprometimento da parede vascular pela reação inflamatória pode determinar modificaçōes locais nas trocas entre o sangue e estruturas circunvizinhas.

Assim sendo, é de supor que as trocas entre o sangue e o líquido cefalorraqueano (LCR) possam ser alteradas em decorrência de fenômenos vasculiticos que venham a ocorrer ao nível dos vasos da piaracnóide. Em conseqüência, poderiam ocorrer modificações na composição do LCR por comprometimento da barreira hêmato-liquórica.

Como podem ocorrer, na esquistossomose mansoni, modif:caçōes profundas do proteinograma do sôro, suficientemente descritas a partir dos estudos de Fiorillo $^{2}$ e de Cardoso ${ }^{1}$, e como são definidas as relações entre o proteinograma do LCR e do sôro em condições normais ${ }^{5}$, foi testada, no presente estudo, a possibilidade de haver modificações do proteinograma do LCR na esquistossomose mansoni passíveis de ser atribuídas a comprometimento da barreira hêmato-liquórica.

\section{MATERIAL E MÉTODOS}

O proteinograma do LCR e do soro de 20 pacientes, consecutivamente observados com formas clinicas diversas de esquistossomose mansoni, sem sintomatologia patente de afecçāo do sistema nervoso foram estudados comparativamente e na mesma ocasião.

Trabalho da Clínica Neurológica da Fac. Medicina da Univ. de Sāo Paulo (Prof. H. M. Canelas) apresentado ao IV Congresso Brasileiro de Neurologia (Porto Alegre, julho-1970): * médico-estagiário; * farmacêutico estagiário; ** docente.

Nota dos autores - Parte da aparelhagem utilizada foi custeacia mediante bolsa concedida pela fundação de Amparo à Pesquisa do Estado de São Paulo (FAPESP) ao responsável pelo estudo (A. Spina-França). 
A concentração proteica total e o perfil proteico (eletroforese em papel) foram estudados mediante técnicas anteriormente descritas e interpertados em relação aos valores normais registrados para elas " (*)

\section{RESULT A D S}

A concentração proteica total, as percentagens das fraçōes proteicas no LCR e no soro e as respectivas relaçōes são apresentados nas tabelas 1 e 2 .

\begin{tabular}{|c|c|c|c|c|c|c|c|c|}
\hline \multirow{2}{*}{ Casos } & \multirow{2}{*}{$\begin{array}{l}\text { Proteinas totais } \\
\qquad \mathrm{mg} / 100 \mathrm{ml}\end{array}$} & \multicolumn{7}{|c|}{ Fraçōes (\%) } \\
\hline & & Pré-albumina & albumina & alfa-1 & alfa-2 & beta & tau & gama \\
\hline$=-\cdots$ & $=\ldots$ & $=--=-\therefore$ & - - & $=-$ & $=\cdot=$ & $-\ldots$ & $=-:=$ & $=--=$ \\
\hline 1 & 13 & $\$, 5$ & 34,0 & 5,2 & 9,3 & 21,5 & & 21,5 \\
\hline 2 & 11 & 13,5 & 51,5 & 3,6 & 5,3 & 16,4 & & 9,7 \\
\hline 3 & 21 & 4,0 & 34,0 & 4,4 & 10,6 & 27,5 & & 19,5 \\
\hline 4 & 24 & 4,6 & 44,2 & 6,5 & 10,0 & 20,6 & & 14,1 \\
\hline$\overline{5}$ & 17 & 5,3 & 39,6 & 5,1 & 11,0 & 20,0 & & 19,0 \\
\hline 6 & 9 & 3,8 & 37,0 & 4,6 & 10,4 & 21,2 & & 23,0 \\
\hline 7 & 26 & 1,7 & 40,4 & 5,2 & 9,9 & 27,3 & & 15,5 \\
\hline 8 & 26 & 2,2 & 50,0 & 6,9 & 8,2 & 17,5 & & 15,2 \\
\hline 9 & 14 & 9,2 & 34,6 & 4,7 & $9, \overline{5}$ & 28,0 & & 14,0 \\
\hline 10 & 15 & 6,3 & 38,9 & 4,3 & 9,4 & 29,0 & 4,2 & 7,9 \\
\hline 11 & 13 & 7,8 & 37,5 & 5,3 & 12,0 & 22,0 & 7,2 & 8,2 \\
\hline 12 & 21 & 3,6 & 39,6 & 7,7 & 8,3 & 21,5 & 3,7 & 15,6 \\
\hline 13 & 18 & $2, \overline{\mathbf{J}}$ & 43,0 & 7,2 & 6,5 & 22,8 & 6,2 & 11,8 \\
\hline 14 & 25 & 2,7 & 44,0 & 4,0 & 10,1 & 20,0 & 6,0 & 13,2 \\
\hline 15 & 29 & 3,9 & 54,2 & 3,1 & 6,8 & 12,6 & 7,4 & 12,0 \\
\hline 16 & 26 & 2,6 & 42,0 & 7,1 & 11,2 & 18,9 & 9,6 & 8.6 \\
\hline 17 & 39 & 1.9 & 21,7 & 6,2 & 11,3 & 19,7 & & 39,2 \\
\hline 18 & 24 & 0 & 54,5 & 2,8 & 6,4 & 22,5 & 7,6 & 6,2 \\
\hline 19 & 35 & 2,0 & 34,0 & 4,3 & 8,6 & 24,5 & & 26,6 \\
\hline 20 & 19 & 3,1 & 36,9 & 6,0 & 15,6 & 16,5 & 6,4 & 15,5 \\
\hline
\end{tabular}

Tabela 1 - Proteinas totais e frações no líquido cefalorraqueano.

* Os autores agradecem ao Prof. Vicente Amato Neto a cooperação para selecionar os casos estudados, observados na Clínica de Doenças Tropicais e Infecciosas da Fac. Medicina da Univ. de São Paulo (Serviço do Prof. J. Alves Mreira). 


\begin{tabular}{|c|c|c|c|c|c|c|c|c|c|c|}
\hline \multirow{3}{*}{ N.o } & \multicolumn{6}{|c|}{ Sôro sangüíneo } & \multicolumn{4}{|c|}{$\begin{array}{c}\text { Relação } \\
\text { LCR/Sôro sangüineo }\end{array}$} \\
\hline & \multirow{2}{*}{$\begin{array}{l}\text { Proteinas } \\
\text { totais } \\
\mathrm{g} / 100 \mathrm{ml}\end{array}$} & \multicolumn{5}{|c|}{ Fracōes (\%) } & & & & \\
\hline & & $\begin{array}{l}\text { albu- } \\
\text { mina }\end{array}$ & alfa-1 & alfa-2 & beta & gama & $\begin{array}{l}\text { albu- } \\
\text { mina }\end{array}$ & alfa & beta & gama \\
\hline 1 & 8,2 & 39,0 & 5,3 & 4,8 & 12,8 & 38,1 & 1,09 & 1,43 & 1,68 & 0,56 \\
\hline 2 & 8,4 & 49,4 & 3,8 & 7,4 & 14,9 & 24,5 & 1,32 & 0,79 & 1,10 & 0,40 \\
\hline 3 & 8,9 & 33,3 & 7,6 & 9,4 & 15,7 & 34,0 & 1,14 & 0,88 & 1,75 & 0,57 \\
\hline 4 & 8,0 & 40,0 & 7,2 & 12,4 & 10,8 & 29,6 & 1,22 & 0,84 & 1,91 & 0,48 \\
\hline $\mathbf{5}$ & 8,4 & 36,4 & 4,7 & 9,3 & 14,6 & 35,0 & 1,23 & 1,15 & 1,37 & 0,54 \\
\hline 6 & 8,7 & 37,5 & 5,7 & 10,3 & 17,5 & 29,0 & 1,09 & 0,94 & 1.21 & 0,79 \\
\hline 7 & 8,4 & 28,3 & 11,0 & 8,9 & 13,4 & 38,4 & 1,49 & 0,76 & 2,04 & 0,40 \\
\hline 8 & 8,4 & 34,0 & 6,6 & 15,1 & 12,3 & 32,0 & 1,54 & 0,69 & 1,42 & 0,45 \\
\hline 9 & 7,7 & 38,5 & 6,9 & 10,9 & 13,7 & 30,0 & 1,14 & 0,80 & 2,04 & 0,47 \\
\hline 10 & 8,8 & 39,0 & 4,1 & 7,2 & 12,7 & 37,0 & 1,16 & 1,21 & 2,28 & 0,21 \\
\hline 11 & 8,4 & 40,0 & 7,0 & 8,2 & 18,4 & 26,4 & 1,13 & 1,14 & 1,59 & 0,31 \\
\hline 12 & 8,2 & 49,0 & 3,3 & 8,0 & 14,7 & 25,0 & 0,88 & 1,41 & 1,71 & 0,62 \\
\hline 13 & 8,4 & 44,0 & 3,6 & 10,8 & 11,7 & 29,9 & 1,03 & 0,95 & 2,48 & 0,39 \\
\hline 14 & 8,3 & 43,2 & 5,0 & 9,8 & 12,8 & 29,2 & 1,08 & 0,95 & 2,03 & 0,45 \\
\hline 15 & 7,0 & 59,0 & 2,4 & 5,5 & 7,5 & 25,6 & 0,98 & 1,25 & 2,67 & 0,46 \\
\hline 16 & 7,5 & 44,0 & 4,2 & 7,4 & 9,0 & 35.4 & 1,01 & 1,58 & 3,17 & 0,24 \\
\hline 17 & 7,4 & 37,0 & 5,2 & 5,8 & 15,0 & 37,0 & 0,64 & 1,59 & 1,31 & 1,06 \\
\hline 18 & 8,7 & 53,0 & 5,3 & 5,9 & 8,8 & 27,0 & 1,03 & 0,82 & 3,42 & 0,23 \\
\hline 19 & 7,8 & 44,4 & 5,1 & 5,7 & 12,0 & 32,8 & 0,81 & 1,19 & 2,04 & 0,81 \\
\hline 20 & 6,9 & 55,0 & 4,0 & 8,0 & 13,0 & 20,0 & 0,73 & 1,80 & 1,76 & 0,77 \\
\hline
\end{tabular}

Tabela 2 - Proteinas totais e fracōes no sôro. Relação entre os teores das frações no $L C R$ e no sôro.

No proteinograma do soro foram observadas as modificações classicamente descritas: hiperproteinemia (13 casos) e hipergamaglobulinemia (19 casos).

No proteinograma do LCR foram observadas: hiperproteinorraquia (dois casos) e alterações do perfil proteico, dentre as quais sobressaia o aumento da globulina gama em 10 casos (teores acima de $14 \%$ ).

A relação entre a participação das diversas frações no proteinograma do LCR e do soro (LCR/soro) mostrou: para a albumina relações alteradas em 5 casos, havendo em três aumento da relação (normal $0,8-1,2$ ); para as globulinas alfa relação 
alterada em 5 casos (normal 0,8 - 1,2); para globulina beta relação alterada em 8 casos, havendo diminuição em 4 (normal $1,4-2,1$ ); para globulina gama relação alterada em 8 casos, havendo aumento em 4 (normal $0,4-0,6$ ).

\section{COMENTARIOS}

$\mathrm{Na}$ caracterização de alterações do proteinograma do LCR devidas a modificações da barreira hêmato-liquórica são bem definidos o aumento da relação LCR/sôro de albumina (perfil tipo estase) e o aumento da relação LCR/ sôro para globulina gama. O aumento, neste último caso, oscila entre 0,6 e 1,0. Valores maiores são encontrados quando há produção local dessas globulinas como resultado de reações inflamatórias crônicas próprias ao sistema continente do LCR. Para as globulinas alfa e beta a menor ativirlade da barreira hêmato-liquórica não pode ser suficientemente definida ainda, levando-se em conta os dados reunidos até o presente.

Dentro dos limites impostos por essas considerações verifica-se que dos 20 casos estudados, 6 apresentavam modificaçōes do proteincgrama do LCR passiveis de ser interpretadas como secundárias a comprometimento da barreira hêmato-liquórica: três em que esta se caracterizava por aumento da relação albumina $\mathrm{LCR} /$ sôro (casos 2,7 e 8 ); três em que se caracterizava por aumento da relação gama LCR/sôro (casos 6, 19 e 20).

Os dados apresentados permitem admitir, portanto, a hipótese de que na esquistossomose mansoni podem ocorrer modificações da barreira hêmato-liquórica que podem levar a modificações do proteinograma do LCR.

Aceitando-se esta hipótese com base nos dados descritos verifica-se que nem sempre o aumento da gamaglobulinorraquia pode ser indicativo da vigência de reação inflamatória leptomeningea desencadeada pela presença de ovos do Schistosoma mansoni. Favorável a êsse ponto de vista é a mesma casuística apresentada: dos 10 casos em que havia aumento do teor de globulinas gama no $L C R$ a relação gama $L C R /$ sôro era normal em $\epsilon$. Nesses casos o comportamento da globulina gama não permite admitir a vigência de processo inflamatório leptomeníngeo nem de modificações da barreira hêmato-liquórica pois o aumento no LCR se encontrava dentro da proporção esperada para o aumento existente no sôro (relação LCR/sôro entre 0,4 e 0,6). Dos restantes, em três (casos 6, 19 e 20) o aumento do teor de globulina gama no LCR pode resultar de modificaçōes da barreira hêmato-liquórica. Em um paciente apenas (caso 17) é possível admitir a hipótese de haver reação inflamatória leptomeníngea relacionada à forma nervosa da esquistossomose mansoni, pois nesse caso a relação gama $\mathrm{LCR} /$ sôro se encontrava acima da unidade.

\section{R E S U O}

Estudo comparado do proteinograma do LCR e do sôro sanguíneo de 20 pacientes com esquistossomose mansoni. Foi possivel verificar que as modificações do proteinograma do LCR decorriam das modificações do proteinograma do sôro ou então de modificações da barreira hêmato-liquórica. Estas 
últimas foram caracterizadas em 6 casos. Reações inflamatórias da parede vascular, passiveis de ser observadas na doença são apontadas como a possivel causa de alterações da barreira hêmato-liquórica, por acometimento de vasos da leptomeninge.

O comportamento do teor de globulina gama no LCR encontrava-se aumentado em 10 pacientes: em 6 o aumento era secundário ao aumento do teor no sangue; em três decorria de modificações da barreira hêmato-liquórica; em um era sugestiva de haver reação inflamatória leptomeníngea na possível dependência da esquistossomose mansoni.

\section{S U M M A R Y}

The cerebrospinal fluid proteins in schistosomiasis mansoni

The proteins of cerebrospinal fluid and blood sera were studied in 20 unselected cases of schistosomiasis mansoni. It was found that the changes in the CSF protein fractions are secondary to the changes in the protein fractions of blood sera or result from damage of the blood - CSF barrier. This mechanism explained the changes in protein fractions of CSF in 6 patients. The changes in the blood - CSF barrier were atributed to the impairment of leptomeningeal vessels due to vasculitis that may occur in schistosomiasis.

The gamma globulin content in the CSF was elevated in ten cases : in six it depended of high gamma globulin content in blood sera; in three it depended on changes in the blood - CSF barrier. In one patient the CSF gamma globulin content was suggestive of local inflammatory changes in the leptomeninges, possibly dependent on schistosomiasis mansoni.

1. CARDOSO, W. - As proteinas séricas na esquistossomose forma hepatoesplênica. Med. Cir. Farm. 249:27, 1957.

2. FIORILlo, A. M. - Estudo eletroforético das proteínas séricas na esquistossomiase mansoni forma hepato-esplênica. Tese. São Paulo, 1957.

3. MACIEL, Z.; COELHO, B. \& ABATH, G. - Mielite esquistossomótica (Schistosoma mansoni). Estudo clínico-patológico. An. Fac. Med. Univ. Recife 14:207, 1954.

4. SCAFF, M.; RIVA, D. \& SPINA-FRANÇA, A. - Meningomielorradiculopatia esquistossomótica. Arq. Neuro-Psiquiat. (São Paulo) 29:227, 1971.

5. SPINA-FRANCA, A. - Eletroforese em papel das proteínas do líquido cefalorraqueano. Rev. paulista Med. 59:420, 1961.

Clinica Neurológica - Fac. Med. Univ. São Paulo - Caixa Postal s461 01000 São Paulo SP - Brasil. 